\title{
Cheek Pouch Use, Predation Risk, and Feeding Competition in Blue Monkeys (Cercopithecus mitis stuhlmanni)
}

\author{
Lindsey W. Smith, ${ }^{1,2 \star}$ Andres Link, ${ }^{2,3}$ and Marina Cords ${ }^{2,4}$ \\ ${ }^{1}$ Department of Anthropology, City University of New York Graduate Center, New York, NY 10016 \\ ${ }^{2}$ New York Consortium in Evolutionary Primatology (NYCEP), New York, NY \\ ${ }^{3}$ Department of Anthropology, New York University, New York, NY \\ ${ }^{4}$ Department of Ecology, Evolution and Environmental Biology, Columbia University, New York, NY
}

\begin{abstract}
KEY WORDS Cercopithecidae; foraging strategies; Kenya; predator avoidance; nearest-neighbor dominance score
\end{abstract}

\begin{abstract}
The adaptive function of cheek pouches in the primate subfamily Cercopithecinae remains unresolved. By analyzing the circumstances of cheek pouch use, we tested two hypotheses for the evolution of cercopithecine cheek pouches proposed in earlier studies: (1) cheek pouches reduce vulnerability to predation, and (2) cheek pouches increase feeding efficiency by reducing competition. We studied two groups of wild blue monkeys (Cercopithecus mitis stuhlmanni) in the Kakamega Forest, Kenya, conducting focal observations of feeding individuals. Monkeys were less exposed while emptying their cheek pouches than filling them, supporting the predation-avoidance hypothesis. We investi-
\end{abstract}

Although cercopithecine monkeys are distinguished from other primates by the presence of cheek pouches in which they temporarily store and begin to digest food (Murray, 1975), the adaptive function of cheek pouches has not been conclusively determined. As Lambert (2005) noted recently, few studies have quantified cheek pouch use and related it systematically to environmental or social variables that might shed light on its adaptive function. Even fewer studies have been conducted on primates living in natural environments. We aimed to test two nonexclusive hypotheses about cheek pouch use suggested by earlier research, using detailed observations of the foraging behavior of wild blue monkeys (Cercopithecus mitis stuhlmanni). Cheek pouch use may (1) reduce vulnerability to predation by allowing quick acquisition of food and retreat to safer positions to process food, and/or (2) increase feeding efficiency by reducing intra and/or interspecific feeding competition. These hypotheses derive from the facts that primates forage gregariously and often in polyspecific associations (which can foster competition both within and between species) and that they are frequently vulnerable to predators while foraging (Murray, 1975; Lambert, 2005).

Supporting the predation-avoidance hypothesis, Lambert (2005) reported that Cercopithecus ascanius and Lophocebus albigena in the Kibale National Park, Uganda, retreated to safer places after filling their cheek pouches. Furthermore, L. albigena lived in smaller groups (suggesting reduced within-group feeding competition), yet they used their cheek pouches more frequently than C. ascanius (Lambert, 2005). In a study of three wild guenon species (C. campbelli, C. petaurista, gated several measures of competitive threat, but only one supported the competition-reduction hypothesis: when the nearest neighbor's rank increased, subjects were more likely to increase than to decrease cheek pouch use. Overall, our findings supported the predation-avoidance hypothesis more strongly than the competition-reduction hypothesis. We suggest that variation in cheek pouch use may reflect differing behavioral strategies used by cercopithecines to mitigate competition and predation, as well as factors such as resource size and distribution, home range size, and travel patterns. Am J Phys Anthropol 137:334-341, 2008. ๑2008 Wiley-Liss, Inc.

C. diana) in the Tai National Park, Côte d'Ivoire, Buzzard (2006) reported that $C$. campbelli had less distended cheek pouches when feeding in association with $C$. diana than when feeding without $C$. diana, a pattern that supports the predator-avoidance function of cheek pouch use if mixed-species associations reduce the risk of predation (Wolters and Zuberbühler, 2003).

Support for the competition-reduction hypothesis has been somewhat mixed. Hayes et al. (1992) found that all age-sex classes of wild Papio ursinus in the Mkuzi Game Reserve, South Africa, used their cheek pouches more frequently during mid-day periods when they spent most time feeding and the potential for competition was high. Additionally, cheek pouch use decreased with advancing age for both males and females, and adult females used their cheek pouches more than males did. Although these results are consistent with the idea that competi-

Grant sponsor: New York Consortium in Evolutionary Primatology (NSF IGERT Grant); Grant number: 0333415; Grant sponsor: NSF; Grant numbers: 9808273, 0554747; Grant sponsor: AAAS Grant.

\footnotetext{
*Correspondence to: Lindsey Smith, Department of Anthropology, CUNY Graduate Center, 365 Fifth Avenue, New York, NY 10016. E-mail: lindseywsmith@yahoo.com
}

Received 16 December 2007; accepted 9 May 2008

DOI 10.1002/ajpa.20879

Published online 8 July 2008 in Wiley InterScience (www.interscience.wiley.com). 
tively disadvantaged individuals use cheek pouches most often, the effects of dominance rank in males appeared contradictory: higher-ranking males used cheek pouches more frequently than lower-ranking males. Among adult females, however, there was no relationship between rank and cheek pouch use (Hayes et al., 1992).

Lambert (2005) found that L. albigena and C. ascanius used cheek pouches more often when feeding on more contestable foods (namely fruits), and when in the presence of a larger number of conspecifics. There were no age-sex class differences in cheek pouch use among $L$. albigena, but $C$. ascanius subadults used their cheek pouches less than adults, perhaps because the subadult diet included more insects, a food less likely to be placed in cheek pouches (Lambert, 2005). Studying captive adult Papio cynocephalus, Lambert and Whitham (2001) found that cheek pouch use increased when the animals were provisioned and competitive interactions were frequent (also Hannibal and Rodrigues, 2007). In addition, lower-ranking animals used their cheek pouches more than higher-ranking animals, and females used cheek pouches more than males. These results support the competition-reduction hypothesis, although they differ from the study of $P$. ursinus with respect to dominance effects (Hayes et al., 1992).

Lambert and Whitham (2001) found that, overall, cheek pouches have been used more often in captive baboons than in wild ones $(59 \%$ vs. $28 \%$ of feeding records), and they suggested that the extremely clumped food available in captivity leads to a reliance on cheek pouches to minimize within-group contest competition for food. Hayes et al. (1992) noted similarly that cheek pouch use in wild baboons varied with the distribution of food. Their study, conducted at a time of year when food was clustered in fruiting trees, revealed a higher frequency of cheek pouch use than previous observations of wild baboons eating more widely dispersed foods such as grasses and roots (Altmann and Altmann, 1970). More clumped food is often viewed as enhancing the potential for competition.

We investigated the influence of predation risk and intraspecific competition on cheek pouch use in two groups of wild blue monkeys (C. mitis stuhlmanni) living in adjacent and partially overlapping home ranges. Blue monkeys are primarily arboreal, forest-dwelling omnivores, although their diets consist mainly of fruits, leaves, and to a lesser extent, invertebrates (Cords, 1987; Lawes, 1991; Chapman et al., 2002). We tested the predationavoidance hypothesis by comparing the exposure of animals to potential aerial predators when filling versus emptying their cheek pouches. To test the competitionreduction hypothesis, we used information on the distance to nearest neighbors, number of other conspecifics nearby, and the relative dominance rank of the subject and its nearest neighbor. The current research builds upon previous studies of wild forest-dwelling guenons (especially Lambert, 2005) by introducing data from a different species and including information on dominance ranks as an added measure of competitive threat.

\section{METHODS}

\section{Study site and subjects}

We studied two groups of blue monkeys, GN and GS, at the Isecheno study site of the Kakamega Forest, western Kenya. This study site $\left(0^{\circ} 19^{\prime} \mathrm{N} 34^{\circ} 52^{\prime} \mathrm{E}\right.$; Elev. $\left.1,650 \mathrm{~m}\right)$ is in the main block $\left(24 \mathrm{~km}^{2}\right)$ of the Kakamega Forest.
The forest's native vegetation is a semideciduous type of Guineo-Congolian lowland rainforest (Cords, 1987), and the study site includes primarily this type of vegetation in near-natural and secondary stages (Lung, 2004). Blue monkeys at Isecheno are sympatric with $C$. ascanius, Colobus guereza, and Perodicticus potto (Cords, 1987). They occur at a density of 220 individuals $/ \mathrm{km}^{2}$ (5 groups $/ \mathrm{km}^{2}$; Fashing and Cords, 2000), a relatively high density for the species (Lawes et al., in press). The two study groups had neighboring home ranges of approximately 19 ha (GS) and 16 ha (GN), including a six hectare area of overlap.

The two groups originated from a single parent group that had been studied intermittently since 1993 and continuously since 1997 . The parent group split into GN and GS in 1999. In 2004, when we conducted our study, GN included 10 adult females, five juvenile males, and two juvenile females, while GS had 19 adult females, six juvenile males, and nine juvenile females. Each group also included just one resident male, the modal number for the species (Cords, 2000a). Our subjects included all group members over the age of 2 years. All subjects could be individually recognized based on physical features.

\section{Data collection}

We collected data from our study groups between 0700 and $1800 \mathrm{~h}$ from June 27 through August 14, 2004 (31 observation days for GS, 21 observation days for GN). We conducted focal animal samples, making instantaneous records at 2-min intervals. Focal subjects were never sampled more than once per day to maximize independence of samples. We also tried to maximize the time between samples of each subject by rotating through most group members before resampling any one of them. Focal samples began when the subject started to ingest food and lasted $20 \mathrm{~min}$ if no cheek pouches were filled, or past the 20-min mark if cheek pouches were filled (see later). Sometimes feeding activity was continuous during the entire sample, whereas in other cases it was interrupted by other activities such as resting or grooming. With the exception of the description of the subjects' diet during our study, our analyses included only those samples in which feeding occupied at least half of the initial $20 \mathrm{~min}$. The average number of such samples per individual was $3.9 \pm 1.4$ for 18 subjects in GN, and 5.1 \pm 2.2 for 35 subjects in GS. Total focal sampling duration was $73.5 \mathrm{~h}$ for GS and $25.5 \mathrm{~h}$ for GN.

During a focal animal sample, we recorded the following data every 2 min: the subject's activity (feeding, resting, moving, or social activities), the food item consumed (fruits, leaves, flowers, seeds, insects, or other), the plant species (when possible), and the subject's cheek pouch volume. Cheek pouch volume was measured on a threepoint scale: zero (empty), one (partly full), two (full). Focal samples were extended past $20 \mathrm{~min}$ if the subject had achieved a check pouch volume greater than zero at the 20-min mark. In such cases, observations continued until the subject reduced its cheek pouch volume by at least one point on the three-point scale. This practice enabled us to compare the socio-ecological conditions within a single period of filling and then emptying cheek pouches. We also recorded "emptying" cheek pouches during any interval in which the subject adjusted cheek pouch contents by pushing around food inside the cheek pouch with the fingers, or by shifting the mouth or neck 
to reposition food inside the check pouch when such actions were followed by chewing or swallowing.

\section{Vulnerability to predation}

Among known predators of blue monkeys (Lawes et al., in press), the African crowned eagle (Stephanoaetus coronatus) appears to be the most important at Kakamega. These birds are seen or heard regularly (Cords, 1987, 2002), although attacks on the study groups are rarely witnessed. No successful attack has been observed in the past 29 years of research in this area (Cords, 2002), including the period of this study. However, two GN animals disappeared (later in 2004 and in 2006) after an eagle was observed to harass their group repeatedly over a period of days. Furthermore, blue monkeys are extremely vigilant to raptors, especially eagles, and respond to them by alarm calling and leaping down into thick vegetation (Cords, 1987; Cordeiro, 1992). Alarms to potential aerial predators occur on a near daily basis.

Other confirmed or suspected predators of blue monkeys occurring at Kakamega are Gaboon vipers (Bitis gabonica), humans, and domestic dogs. The only confirmed case of predation in 29 years involved a Gaboon viper (Foerster, pers. comm.). On the basis of dozens of other snake encounters, however, it seems clear that snakes are almost always discovered and then avoided well before they would actually be dangerous. Human poaching (with or without dogs) is extremely rare, and the monkeys were well habituated to humans at the time of this study. For these reasons, we believe that aerial predation predominates at Kakamega, and has the greatest potential to influence the monkeys' behavior.

We assumed that a subject's vulnerability to aerial predation is related to its exposure (Cowlishaw, 1997a), and following Lambert (2005), we assigned a "safety of position" score to the focal subject based on three variables. One was the height of the feeding tree relative to surrounding trees, which we divided into four categories: emergent (crown above the upper layer of the surrounding canopy), canopy (crown in the upper level of the forest, independent of the tree's actual height, but excluding vegetation in open areas), sub canopy (crown between the understory and canopy), and ground/understory (on/near the forest floor or in shrubby vegetation). Second, we defined the focal animal's position within the crown as edge if the subject was $<2 \mathrm{~m}$ from the terminal branchlets, and interior otherwise. Finally, foliage density was classified as high (subject hard to see in dense foliage) or low (subject easily visible in scarce or light foliage). The variables we chose differed somewhat from Lambert (2005) but were easier to assess at our field site. We used Lambert's method of combining these variables into a vulnerability scale ranging from 1 to 16 (Table 1).

\section{Intraspecific competition}

Our analyses of competitive pressure focused on the dominance rank of the subject, as well as the proximity and relative dominance rank of individuals near the subject when it was feeding. In blue monkey society, adult males essentially always dominate other group members. The dominance ranks of all remaining individuals were based on decided dyadic agonistic interactions that occurred within each group from 1999 to 2004 (Cords, unpublished data), with ranks computed by the program
TABLE 1. Predation vulnerability index, ranging from

1 (most safe/least-exposed) to 16 (least safe / most-exposed; after Lambert, 2005)

\begin{tabular}{cccc}
\hline 1 & 2 & 3 & 4 \\
Ground/Understory & Subcanopy & Canopy & Emergent \\
Interior & Interior & Interior & Interior \\
High & High & High & High \\
5 & 6 & 7 & 8 \\
Ground/Understory & Subcanopy & Canopy & Emergent \\
Edge & Edge & Edge & Edge \\
High & High & High & High \\
9 & 10 & 11 & 12 \\
Ground/Understory & Subcanopy & Canopy & Emergent \\
Interior & Interior & Interior & Interior \\
Low & Low & Low & Low \\
13 & 14 & 15 & 16 \\
Ground/Understory & Subcanopy & Canopy & Emergent \\
Edge & Edge & Edge & Edge \\
Low & Low & Low & Low \\
\hline
\end{tabular}

Each cell represents a unique combnation of values for tree's position in the canopy (emergent, subcanopy, canopy), monkey's position within the crown (edge, interior), and foliage density (high, low).

MatMan (Noldus; hierarchies for each group were significantly linear, $P<0.05$ ). We recorded the distance to the subject's nearest neighbor (and its identity, when possible) and, as an alternative measure of competitive pressure, the number of individuals in or within $3 \mathrm{~m}$ of the subject's feeding tree. We refer to such individuals as "nearby." We measured distances visually to the nearest meter; any distance beyond $20 \mathrm{~m}$ was recorded as $>20 \mathrm{~m}$.

We categorized feeding trees as small, medium, or large based on visual estimates of how many monkeys could fit simultaneously within the tree if they maintained typical inter-individual distances (Cords, 2002). Small feeding trees could hold up to four monkeys (e.g., the understory shrub Solanum mauritianum), whereas medium trees could hold between five and nine monkeys (e.g., the tree Psidium guajava), and large trees could hold 10 or more monkeys (e.g., the canopy tree Maesopsis eminii).

\section{Data analysis}

We used individual focal samples as the basic unit in our analyses. To characterize which food items were most often placed in cheek pouches, we classified each sample according to the one food item (e.g., fruit, leaves, or insects) that was eaten for at least $75 \%$ of the time in which the subject was feeding. This practice helped us to capture accurately the main food item that was actually filling the cheek pouches rather than minor items swallowed intermittently. Samples in which no item was eaten $>75 \%$ of the time were excluded from this analysis.

To compare the circumstances in which cheek pouches were filled and emptied, we first classified instantaneous records as "filling" when the subject was feeding, or had been feeding during the preceding interval, and when its cheek pouches were distended (scored one or two) at the end of a series of such "filling" records. Instantaneous records were classified as "emptying" when the subject actively extracted food from its cheek pouches during the previous 2-min interval and did not ingest anything new. Some records were preceded by intervals that included both filling and emptying, but these were excluded from our comparison of filling vs. emptying circumstances. To 


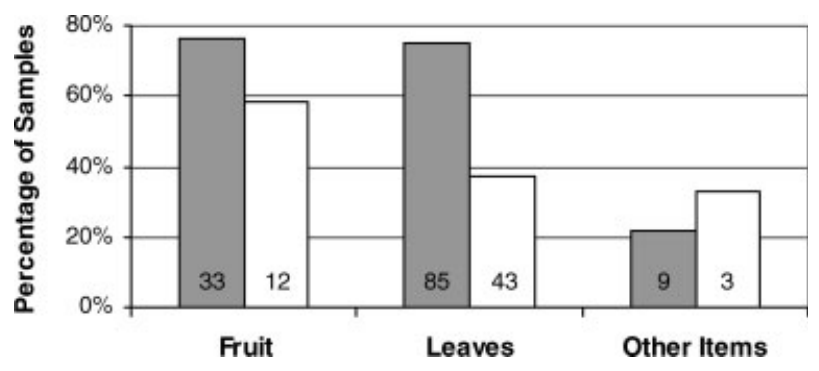

Fig. 1. Percentage of samples that included cheek pouch use according to the predominant food item consumed. GS is represented by the dark bars, GN by the white bars. Numbers within bars are the numbers of samples that served as a basis for the percentage reported.

compare vulnerability to predators when cheek pouches were being filled or emptied, we used samples in which both filling and emptying occurred, computing average vulnerability scores for each of the two circumstances in each sample, and comparing those values with a Wilcoxon Matched Pairs Signed Ranks test.

We compared the average distance from the subject (while feeding) to its nearest neighbor (NN), as well as the number of "nearby" individuals, for focal samples in which cheek pouches were or were not used. This analysis controlled for tree size, and we assigned to each sample the tree size that the subject used most frequently for feeding. We also made a within-sample comparison of the average distance to the NN and the average number of nearby individuals by comparing periods when cheek pouches were distended versus empty in the same sample. Records following intervals in which both filling and emptying had occurred were again omitted. Finally, we compared cheek pouch use in samples when subjects had neighbors within a $20 \mathrm{~m}$ distance (at any time within the sample) versus samples when subjects never had a neighbor within $20 \mathrm{~m}$.

To determine whether blue monkeys used their cheek pouches more when a higher-ranking monkey was nearby, we scored a "one" on each instantaneous record when the NN was higher ranking than the subject and "zero" when the NN was lower ranking. We averaged these scores across a sample to create a NN Dominance Index for that sample which varied from zero to one: an index value of 0.5 indicates that a subject had a lower-ranking $\mathrm{NN}$ for half of its feeding time and a higher-ranking $\mathrm{NN}$ the other half of the time. We assumed that higher index values would reflect greater competitive pressure.

\section{RESULTS \\ Diet composition and frequency of cheek pouch use}

Combining all data from instantaneous feeding records (in the first $20 \mathrm{~min}$ of each sample only) across groups and age/sex classes ( $N=1,932$ point records, representing $64.5 \mathrm{~h}$ of feeding time), we found that leaves were eaten most often ( $61 \%$ of records) during the study period, followed by fruit $(25 \%)$, insects $(6 \%)$, flowers $(4 \%)$, and other items $(3 \%)$. While there were only two adult males among our subjects (one per study group), they differed from other group members in that both ate more fruit than leaves. The proportion of samples including cheek pouch use was no different for fruit- versus leaf-
TABLE 2. Number and percentage of samples in which animals moved to safer, equally safe, or less safe positions to empty their cheek pouches after filling them

\begin{tabular}{lrccr}
\hline Group & $N$ & $\begin{array}{c}\text { Move to } \\
\text { a safer } \\
\text { position }\end{array}$ & $\begin{array}{c}\text { Move to } \\
\text { an equally } \\
\text { safe position }\end{array}$ & $\begin{array}{c}\text { Move to } \\
\text { a less safe } \\
\text { position }\end{array}$ \\
\hline GS & 114 & $68(60 \%)$ & $5(4 \%)$ & $41(36 \%)$ \\
GN & 23 & $15(65 \%)$ & $3(13 \%)$ & $5(22 \%)$ \\
Total & 137 & $83(61 \%)$ & $8(6 \%)$ & $46(34 \%)$ \\
\hline
\end{tabular}

$\mathrm{N}$, number of samples in which cheek pouches were filled and subsequently emptied. Predator vulnerability was assessed using the index in Table 1. Both groups showed a significant tendency to move to a safer position (see text).

feeding within either group (Fig. 1; GS: $\chi^{2}=0.003, P>$ 0.15; GN: $\left.\chi^{2}=1.72, P>0.15,1 \mathrm{df}\right)$. GS, however, generally used cheek pouches more often than GN (72\% of 127 samples vs. $41 \%$ of 58 samples, $\chi^{2}=15.52, P<0.01,1 \mathrm{df}$ ). When we examined between-group differences for the major dietary components, we found no difference in cheek pouch use while feeding on fruit, whereas the between-group difference was significant for leaf-feeding, with GS individuals using their cheek pouches almost twice as often as GN individuals (Fig. 1, $\chi^{2}, P<0.01$ ).

\section{Vulnerability to predation}

Our subjects most often moved towards a less exposed (safer) position when emptying their cheek pouches (Table 2, Binomial test, $P<0.01$ for GS, $P<0.05$ for GN). Thus, vulnerability scores were higher as the monkeys filled their check pouches relative to when they emptied them (mean exposure score: $7.2 \pm 3.1$ filling versus $5.9 \pm 3.8$ emptying; Wilcoxon Matched Pairs Signed Rank Test, $Z=3.17, P<0.01, N=137$ samples that included both filling and emptying). This same pattern held for each group analyzed separately as well (GS filling, $7.4 \pm 3.8$ vs. emptying $6.1 \pm 3.9$, Wilcoxon Matched Pairs Signed Ranks Test, $Z=-3.12, P<0.01$, $N=114$; GN filling $6.0 \pm 3.5$ vs. emptying $4.7 \pm 3.3$; Wilcoxon Matched Pairs Signed Ranks Test, $Z=-1.98$, $P<0.05, N=23)$. We also found higher exposure scores overall during feeding in GS $(7.2 \pm 3.7, N=168)$ than in GN $\left(5.8 \pm 3.5, N=62\right.$; Mann Whitney U test, $Z_{\text {corr }}=$ -3.28 , two-tailed $P<0.01$; only the first $20 \mathrm{~min}$ of each sample were included in this analysis), although the two groups did not differ in vulnerability when we restricted analysis to samples in which leaves were the predominant food (Mann Whitney $\mathrm{U}$ test, $Z_{\text {corr }}=1563.5, Z_{\text {corr }}=$ $-0.94, P>0.15, \mathrm{~N}=10 \mathrm{GN}$ and $33 \mathrm{GS}$ samples).

Our subjects did not seem to fill their cheek pouches very rapidly, as observed in some rodents (Chaetodipus formosus and Dipodomys panamintinus; Vander Wall et al., 1998) and in captive rhesus macaques (Macaca mulatta; Cords, pers. obs.). Rather, cheek pouches were generally filled more subtly in the course of steady feeding, after which the animals moved at an average pace to a less-exposed location where they emptied the cheek pouches slowly while thoroughly chewing the food and sometimes spitting out seeds.

\section{Intraspecific competition}

We analyzed distance to the NN separately for small, medium, and large feeding trees, as tree crown size is likely to influence the distance between groupmates. 
TABLE 3. Median distance to the nearest neighbor in samples that included or did not include cheek pouch use for both social groups

\begin{tabular}{|c|c|c|c|c|c|c|c|c|c|}
\hline \multirow[b]{2}{*}{$\begin{array}{l}\text { Tree } \\
\text { size }\end{array}$} & \multirow[b]{2}{*}{$\begin{array}{l}\text { Cheek } \\
\text { pouch } \\
\text { use }\end{array}$} & \multicolumn{4}{|c|}{ GS study group } & \multicolumn{4}{|c|}{ GN study group } \\
\hline & & $\begin{array}{c}\text { Median distance } \\
\text { to nearest } \\
\text { neighbor }(\mathrm{m})\end{array}$ & $\begin{array}{l}\text { Interquartile } \\
\text { range }\end{array}$ & $N$ & $\begin{array}{l}\text { Mann } \\
\text { Whitney } \\
\text { U test }\end{array}$ & $\begin{array}{c}\text { Median distance } \\
\text { to nearest } \\
\text { neighbor }(\mathrm{m})\end{array}$ & $\begin{array}{l}\text { Interquartile } \\
\text { range }\end{array}$ & $N$ & $\begin{array}{c}\text { Mann } \\
\text { Whitney } \\
\text { U test } \\
\end{array}$ \\
\hline \multirow[t]{2}{*}{ Large } & No & 6.5 & $4.7-9.7$ & 16 & $U=255.5$ & 7.6 & $4.3-16.8$ & 16 & $U=95.5$ \\
\hline & Yes & 6.5 & $4.7-9.2$ & 32 & $P=0.99$ & 7.4 & $3.0-14.4$ & 13 & $P=0.71$ \\
\hline \multirow{2}{*}{ Medium } & No & 8.3 & $4.6-11.3$ & 14 & $U=74.5$ & 15.8 & $5.1-20.0$ & 17 & \\
\hline & Yes & 5.0 & $4.4-9.0$ & 15 & $P=0.18$ & 1.9 & NA & 1 & No test \\
\hline \multirow[t]{2}{*}{ Small } & No & 8.6 & $5.4-11.6$ & 23 & $U=743.5$ & 4.7 & $2.8-19.3$ & 7 & $U=38$ \\
\hline & Yes & 6.5 & $5.0-9.4$ & 78 & $P=0.21$ & 8.7 & $5.7-20.0$ & 16 & $P=0.23$ \\
\hline
\end{tabular}

To characterize each sample, we included only those instantaneous records that matched the tree size used most often for feeding. $N$, number of samples.

TABLE 4. Median number of nearby individuals in samples that included or did not include cheek pouch use for both social groups

\begin{tabular}{|c|c|c|c|c|c|c|c|c|c|}
\hline \multirow[b]{2}{*}{$\begin{array}{l}\text { Tree } \\
\text { size }\end{array}$} & \multirow[b]{2}{*}{$\begin{array}{l}\text { Cheek } \\
\text { pouch } \\
\text { use }\end{array}$} & \multicolumn{4}{|c|}{ GS study group } & \multicolumn{4}{|c|}{ GN study group } \\
\hline & & $\begin{array}{c}\text { Median number } \\
\text { of nearby } \\
\text { individuals }\end{array}$ & $\begin{array}{l}\text { Interquartile } \\
\text { range }\end{array}$ & $N$ & $\begin{array}{l}\text { Mann } \\
\text { Whitney } \\
\text { U test }\end{array}$ & $\begin{array}{l}\text { Median number } \\
\text { of nearby } \\
\text { individuals }\end{array}$ & $\begin{array}{l}\text { Interquartile } \\
\text { range }\end{array}$ & $N$ & $\begin{array}{l}\text { Mann } \\
\text { Whitney } \\
\text { U test }\end{array}$ \\
\hline \multirow[t]{2}{*}{ Large } & No & 2.9 & $1.5-3.9$ & 17 & $U=271.5$ & 1.5 & $0.5-3.6$ & 13 & $U=62$ \\
\hline & Yes & 2.4 & $1.3-3.7$ & 33 & $P=0.85$ & 1.8 & $1.0-4.6$ & 13 & $P=0.25$ \\
\hline \multirow[t]{2}{*}{ Medium } & No & 1.7 & $1.3-2.0$ & 14 & $U=79$ & 0.8 & $0.1-3.1$ & 16 & No test \\
\hline & Yes & 1.9 & $1.5-2.3$ & 15 & $P=0.26$ & 3.0 & NA & 1 & \\
\hline \multirow[t]{2}{*}{ Small } & No & 1.1 & $1.0-1.3$ & 22 & $U=780.5$ & 1.3 & $0.7-1.9$ & 7 & $U=43$ \\
\hline & Yes & 1.1 & $1.0-1.3$ & 80 & $P=0.42$ & 1.0 & $0.1-1.3$ & 16 & $P=0.39$ \\
\hline
\end{tabular}

To characterize each sample, we included only those instantaneous records that matched the tree size used most often for feeding. $N$, number of samples.

Neither group showed a difference in the average NN distance in the samples of subjects who used their cheek pouches relative to those who did not use them (Table 3 ). Similarly, a comparison within samples of periods when cheek pouches were being filled versus emptied showed no difference in the distance to the $\mathrm{NN}(6.97 \pm 3.62 \mathrm{~m}$ during filling versus $6.65 \pm 3.91 \mathrm{~m}$ during emptying; Wilcoxon Matched Pairs Signed Ranks Test, $Z=-1.158$, $P>0.15, N=92$ samples).

Like the analysis of NN distance, our analysis of the number of nearby individuals controlled for tree size. Neither group showed significant differences in the number of nearby individuals in samples with cheek pouch use versus those without cheek pouch use (Table 4). When we compared within samples the periods of cheek pouch filling versus emptying, however, there were more individuals nearby when the cheek pouches were being filled (1.25 \pm 1.68 individuals) versus emptied (0.80 \pm 1.07 individuals; Wilcoxon Matched Pairs Signed Ranks Test, $Z=-2.221, P<0.05, N=70$ samples).

We further compared samples in which groupmates were $\leq 20 \mathrm{~m}$ from the subject at some time to those in which the subject was always $>20 \mathrm{~m}$ away from any other conspecific. Cheek pouches were used in a larger proportion of samples in which groupmates were within $20 \mathrm{~m}$ (138 of $204,68 \%)$ than when no groupmates were within $20 \mathrm{~m}\left(18\right.$ of $\left.45,40 \% ; \chi^{2}=12.04, P<0.01\right)$. At distances $<20 \mathrm{~m}$, however, we did not see a decrease in the likelihood of cheek pouch use as $\mathrm{NN}$ distance increased (see Fig. 2). Over the course of our study, we recorded only two instances of blue monkeys feeding within $10 \mathrm{~m}$ of another primate species (in both cases it was $C$. guereza) during a focal sample. Thus, members of other spe-

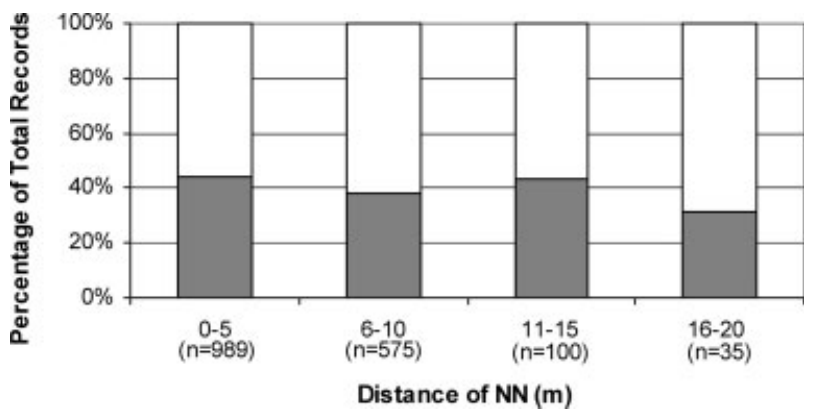

Fig. 2. Percentage of time that cheek pouches were used as a function of distance to the NN. Shaded bars represent cheek pouch use, white bars represent no cheek pouch use. $N$, the number of feeding records at each distance.

cies were not found to be competitive threats to blue monkeys in our samples.

When we limited our analysis of NN to those ranking higher than the subject, we found no effect of their presence on the use of cheek pouches. Specifically, the Nearest Neighbor Dominance Index was not consistently related to the proportion of samples in which subjects used their cheek pouches (see Fig. 3). We also examined 22 cases in which the subject went from having a lowerranking $\mathrm{NN}$ to having a higher-ranking $\mathrm{NN}$ over the course of a single sample. In half these cases, there was no concomitant change in cheek pouch use; however, when a change occurred, it was much more likely to be an increase in cheek pouch use (9 of 22$)$ than a decrease ( 2 of 22 ; Binomial test, $P<0.05$ ). 


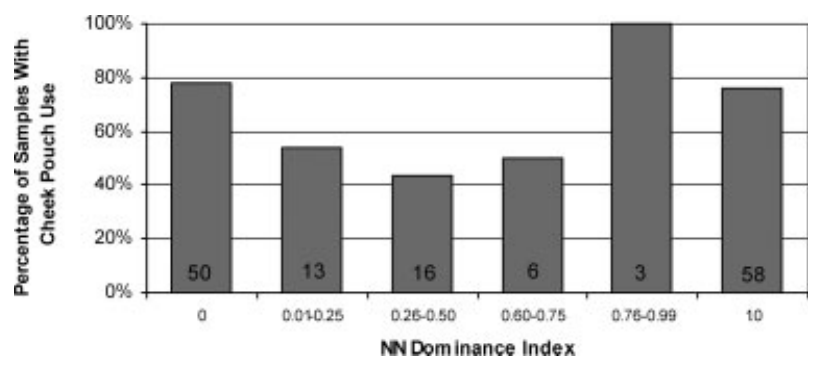

Fig. 3. Cheek pouch use as a function of the relative rank of NNs. Data presented come from 103 samples in which cheek pouches were used and the dominance ranks of the NNs were known. The NN Dominance Index varied from 0 (NN always lower ranking than subject) to 1 (NN always higher ranking). Numbers within bars are the number of samples on which the percentages are based.

We examined whether the subject's own dominance rank affected cheek pouch use, and found no significant correlation between dominance rank and the proportion of samples in which cheek pouches were used for either group (GS: $r_{\mathrm{s}}=-0.285, N=26$, one-tailed $P>0.05$; GN: $r_{\mathrm{s}}=-0.004, N=12$, one-tailed $P>0.15$; subjects were included only if they had been sampled at least three times).

To see if between-group differences in cheek pouch use could be ascribed to differences in within-group feeding competition, we compared the NN distances of GS and GN subjects. The average distance to the $\mathrm{NN}$ was smaller for GS subjects (GS: $7.6 \pm 3.9 \mathrm{~m}, N=177$ samples; GN: $10.4 \pm 6.2 \mathrm{~m}, N=71$ samples; Mann Whitney $U=4865, Z_{\text {corr }}=-2.78, P<0.01$ ), matching their more frequent cheek pouch use. However, there were more individuals nearby the focal animals in GN $(1.33 \pm 1.8$, $N=71)$ compared to GS $(0.85 \pm 1.3, N=177$ samples; Mann Whitney $U=5014.5, Z_{\text {corr }}=-2.51, P<0.01$ ). There was no difference between groups in the Nearest Neighbor Dominance Index (GS: mean $=0.52, N=117$ samples; GN: mean $=0.41, N=29$ samples, $U=$ $1897.5, P>0.15)$. We repeated all three analyses considering only those samples in which the subject fed on leaves, and the same differences emerged for NN distance (Mann Whitney $U=1,309, Z_{\text {corr }}=-2.79, P<$ 0.01 ) and number of nearby individuals ( $U=1278.5$, $\left.Z_{\text {corr }}=-2.97, P<0.01\right)$. The Nearest Neighbor Dominance Index again showed no differences between the two groups $\left(U=476, Z_{\text {corr }}=-0.91, P>0.15\right)$.

\section{DISCUSSION}

Our results support the hypothesis that cheek pouches are used to reduce exposure to aerial predation, and provide more limited support for the competition-reduction hypothesis.

Both of our study groups used a retrieve-and-retreat (Murray, 1975) feeding strategy in which individuals often emptied their cheek pouches in a less vulnerable position than where they filled them. Our findings thus support conclusions of previous studies that evaluated the predation-avoidance hypothesis in cercopithecine monkeys (Lambert, 2005; Buzzard, 2006). Moving to an area with high foliage density, closer to an understory tree's trunk, is a behavior demonstrated to reduce exposure to predation in many arboreal primates (Isbell, 1994). Although few cases of predation have been documented in our study population or others, the finely tuned vigilance and predator-avoidance behavior of individuals in wild populations (Cowlishaw, 1997b; Cords, 2002; Shultz and Noë, 2002) as well as the regular formation of polyspecific associations (Cords, 1987; Gautier-Hion, 1988; Wolters and Zuberbühler, 2003) suggest that the monkeys perceive the threat as real and practice various avoidance strategies. Predation risk, measured according to the presence of predators, the protective responses of their primate prey, and observed predation attempts, has been shown to influence important aspects of primate social grouping, including group size and the number of adult males (Hill and Dunbar, 1998; Hill and Lee, 1998).

The less robust support that our results give to the competition-reduction hypothesis also agrees with previous studies, which collectively have not consistently confirmed its predictions. Many investigations of the competition-reduction hypothesis have related cheek pouch use to the presence of individuals - either conspecifics or heterospecifics-near the subject while feeding, expecting to find a correlation. It is not necessarily true, however, that animals feeding in closer proximity to others are competing more for food: food may be plentiful (at least locally), and the distribution of feeding animals may simply mirror the distribution of food. Additionally, animals may be feeding in close proximity to take advantage of safety in numbers when predation risk is perceived as high. Most of our results that support the competitionreduction hypothesis are of this nature: that is, we found some evidence that animals feeding nearer their groupmates used their cheek pouches more often.

Stronger predictions of the competition-reduction hypothesis relate cheek pouch use directly to measures of competitive ability (such as dominance rank for withinspecies competition) or actual competitive interaction. We investigated several measures related to the dominance rank of our subjects or of their $\mathrm{NNs}$, but only one supported the competition-reduction hypothesis (namely that when a neighbor's rank increased, subjects were more likely to increase than to decrease cheek pouch use, but half the time there was no change either way). Other studies have also reported inconsistent and sometimes conflicting results when cheek pouch use is related to dominance rank. For example, Lambert and Whitham (2001) found that lower-ranking individuals used their cheek pouches more than higher-ranking individuals, while Hayes et al. (1992) found no rank effect among females, and the reverse effect (more cheek pouch use by higher-ranking individuals) among males. Higher-ranking males may use their cheek pouches more often because the demands of vigilance or male-male competition for females force them to limit time spent feeding. Future studies using rank relations of near neighbors as indicators of competitive pressure may also wish to control for kinship.

Buzzard (2006) simultaneously evaluated the predation-avoidance and competition-reduction functions of cheek pouch use in Campbell's monkeys (C. campbelli), but focused on between-species competition. C. campbelli used their cheek pouches most when they were not in association with highly vigilant and competitively dominant Diana monkeys (C. diana), a pattern consistent with predation avoidance but not with the reduction of interspecific competition. Buzzard therefore emphasized predation avoidance as the primary factor explaining cheek pouch use in C. campbelli; however, he did not collect data on the number of individuals feeding in close 
proximity or the size of feeding trees, important factors to include in assessing competitive threat more directly. It is possible that shifts in C. campbelli's use of different forest strata mitigated the threat of competition with $C$. diana in association (Buzzard, 2004), and thus that association status does not adequately index the kind of immediate competitive threat that would lead to an increase in cheek pouch use. Buzzard certainly did not reject the possibility that interspecific competition favors the use of cheek pouches in foraging C. campbelli.

The relatively weak support we found for competitive threat driving cheek pouch use in blue monkeys may relate to the foods our study animals were eating at the time of our observations, or to generally low levels of competitive threat in this population throughout the year. Although blue monkeys, like all guenons, are known to include fruit as the largest dietary component over an annual period (Lawes et al., in press; Cords, 1987 this population), our observations took place at a time of year when fruit is often relatively scarce (Cords, pers. obs.). Indeed, leaf-eating was more common than fruit-eating during our samples and Cords (2002) reported a similar pattern for June-August months in other years. Many authors have asserted that competition is weaker when diets are more folivorous as leaves are generally less patchily distributed and more abundant than fruit (Wrangham, 1980; Janson and Goldsmith, 1995; Steenbeek and van Schaik, 2001). Thus, competitive threat may have been especially weak during the time of our observations. In this population, aggressive within-group competition occurs disproportionately when the monkeys feed on fruits but not when they feed on leaves (Cords, 2000b; Pazol and Cords, 2005, data from adult females). Pazol and Cords (2005), however, emphasized that within-group feeding competition is generally weak in Kakamega blue monkeys. They found that the availability of plant reproductive parts influenced the foraging behavior of adult female blue monkeys only slightly, and attributed the weak effect of potential resource competition to the flexible behavioral strategies of the animals, especially their willingness to switch to less preferred and more abundant foods and to spread out while foraging. These alternative strategies for coping with competitive threat may have reduced the importance of using cheek pouches in this context.

Given that cheek pouches may be used for more than one function, an obvious next step is to determine the circumstances in which different types of use occur (Hayes et al., 1992). This is not a trivial problem as animals may use multiple tactics to alleviate predation risk or competitive pressure. Furthermore, cheek pouch use may reflect additional environmental factors not measured in this study. Both Vander Wall et al. (1998) and Lambert (2005), studying rodents and mangabeys respectively, suggested that cheek pouch use can ensure more efficient foraging when animals harvest food more quickly than they can ingest it, and must move long distances between feeding sites. Temporary storage in cheek pouches makes food available even while an animal travels between feeding sites, ensuring a more constant rate of ingestion.

While these authors proposed that between-species differences in movement between feeding sites might therefore influence cheek pouch use, it is conceivable that variation within species could be explained in a similar way. For example, one of our study groups (GS) used cheek pouches more frequently than the other, particularly when feeding on leaves. GS was not more exposed to predators when feeding on leaves than GN, so their greater tendency to use cheek pouches did not seem related to higher predation risk. Competitive pressure may explain the difference between groups if it is best indexed by distance to the NN: other measures of competitive pressure (number of nearby individuals, relative rank of NNs), however, did not indicate that GS individuals faced more competition. It is possible that the between-group difference we observed in cheek pouch use while the monkeys fed on leaves could reflect differences in the distribution of leaf-feeding sites, or general forest physiognomy, rather than fundamental differences in predation risk or competitive environment.

Overall, it seems that cercopithecine cheek pouches may sometimes be used to mitigate both intra- and interspecific feeding competition, while the predator-avoidance function is more universally supported. This generalization may reflect the fact that predation avoidance is more constantly a high priority, while competitionwhether between or within species-is more variable over time. Certainly, these hypotheses are not mutually exclusive, and differences among studies in their support for one or the other may reflect the particular circumstances of study subjects. Important circumstances are likely to include not only predation risk and the threat of competition, but also the various behavioral strategies that monkeys use to cope with these threats. Taxon-specific ranging patterns and habitat preferences, as well as physical features of the habitat (including exposure to potential predators and feeding tree size and distribution) may favor the use of cheek pouches more in some cases than in others. Future studies may be able to evaluate the relative importance of these various factors with comparative data, which are presently very limited.

\section{ACKNOWLEDGMENTS}

We thank Stefan Ekernas, Caleb Makalasia, Brent Pav, and Boniface Shimenga for their assistance in the field. We are also grateful for the advice and critical comments of our reviewers.

\section{LITERATURE CITED}

Altmann SA, Altmann J. 1970. Baboon ecology: African field research. Chicago: University of Chicago Press. p 220.

Buzzard PJ. 2004. Interspecific competition among Cercopithecus campbelli, C. petaurista, and C. diana at Tai Forest, Cote d'Ivoire. Ph.D. dissertation, Columbia University. p 258.

Buzzard P. 2006. Cheek pouch use in relation to interspecific competition and predator risk for three guenon monkeys (Cercopithecus spp.). Primates 47:336-341.

Chapman CA, Chapman LJ, Cords M, Gathua JM, GautierHion A, Lambert JE, Rode K, Tutin CEG, White LJT. 2002. Variation in the diets of Cercopithecus species: differences within forests, among forests, and across species. In: Glenn M, Cords M, editors. The guenons: diversity and adaptation in african monkeys. New York: Kluwer Academic/Plenium Publishers. p 325-350.

Cordeiro NJ. 1992. Behaviour of blue monkeys (Cercopithecus mitis) in the presence of crowned eagles (Stephanoaetus coronatus). Folia Primatologica 59:203-207.

Cords M. 1987. Mixed-species association of Cercopithecus monkeys in the Kakamega forest. Univ California Publ Zool 117:1-109.

Cords M. 2000a. The number of males in guenon groups. In: Kappeler PM, editor. Primate male: causes and consequences of variation in group composition. Cambridge: Cambridge University Press. p 85-96. 
Cords M. 2000b. Agonistic and affiliative relationships in a blue monkey group. In: Whitehead PF, Jolly CJ, editors. Old World monkeys. Cambridge: Cambridge University Press. p 453479.

Cords M. 2002. Foraging and safety in adult female blue monkeys in the Kakamega forest, Kenya. In: Miller LE, editor. Eat or be eaten: predator sensitive foraging among primates. Cambridge: Cambridge University Press. p 205-221.

Cowlishaw GC. 1997a. Refuge use and predation risk in a desert baboon population. Anim Behav 54:241-253.

Cowlishaw GC. 1997b. Trade-offs between foraging and predation risk determine habitat use in a desert baboon population. Anim Behav 53:667-686.

Fashing PJ, Cords M. 2000. Diurnal primate densities and biomass in the Kakamega Forest: an evaluation of census methods and a comparison with other forests. Am J Primatol 50:139-152.

Gautier-Hion A. 1988. Polyspecific associations among forest guenons: ecological, behavioral and evolutionary aspects. In: Gautier-Hion A, Bourliere F, Gautier JP, editors. A primate radiation: evolutionary biology of the African guenons. Cambridge: Cambridge University Press. p 452-476.

Hannibal DL, Rodrigues M. 2007. Feeding competition and cheek pouch use in Macaca mulatta. Am J of Phys Anthropol $\mathrm{S} 44: 125$. [Abstract]

Hayes VJ, Henzi SP, Freedman L, Gaynor D. 1992. The differential use of cheek pouches in a troop of Papio ursinus. Primates 33:477-500.

Hill RA, Dunbar RM. 1998. An evaluation of the roles of predation rate and predation risk as selective pressures on primate grouping behaviour. Behaviour 135:411-430.

Hill RA, Lee PC. 1998. Predation risk as an influence on group size in cercopithecoid primates: implications for social structure. J Zool London 245:447-456.

Isbell LA. 1994. Predation on primates: ecological patterns and evolutionary consequences. Evol Anthropol 3:61-70.

Janson CH, Goldsmith ML. 1995. Predicting group size in primates: foraging costs and predation risks. Behav Ecol 6:326336.
Lambert JE. 2005. Competition, predation, and the evolutionary significance of the cercopithecine cheek pouch: The case of Cercopithecus and Lophocebus. Am J Phys Anthropol 126: 183-192.

Lambert JE, Whitham JC. 2001. Cheek pouch use in Papio cynocephalus. Folia Primatol 72:89-91.

Lawes MJ. 1991. Diet of samango monkeys (Cercopithecus mitis erythrarchus) in the Cape Vidal dune forest, South Africa. J Zool London 224:149-173.

Lawes MJ, Cords M, Lehn C. In press. Cercopithecus mitis profile. In: Butynski TM, Kingdon J, Kalina J, editors. Primates of Africa, Vol. II: The mammals of Africa. London: Academic Press.

Lung T. 2004. Landbedeckungsänderungen im gebiet "Kakamega Forest und assoziierte Waldgebiete" (Westkenia). Karlsruher Geowissenschaftliche Schriften Reihe A 15:1-114.

Murray P. 1975. The role of cheek pouches in Cercopithecine monkey adaptive strategy. In: Tuttle RH, editor. Primate functional morphology and evolution. The Hague: Mouton Publishers. p 151-193.

Pazol K, Cords M. 2005. Seasonal variation in feeding behavior, competition and female social relationships in a forest dwelling guenon, the blue monkey (Cercopithecus mitis stuhlmanni), in the Kakamega Forest, Kenya. Behav Ecol Sociobiol 58:566-577.

Shultz S, Noë R. 2002. The consequences of crowned eagle central-place foraging on predation risk in monkeys. Proc R Soc Lond 269:1797-1802.

Steenbeek R, van Schaik CP. 2001. Competition and group size in Thomas's langurs (Presbytis thomasi): the folivore paradox revisited. Behav Ecol Sociobiol 49:100-110.

Vander Wall SB, Longland WS, Pyare S, Veech JA. 1998. Cheek pouch capacities and loading rates of heteromyid rodents. Oecologia 113:21-28.

Wolters S, Zuberbühler K. 2003. Mixed-species associations of Diana and Campbell's monkeys: the costs and benefits of a forest phenomenon. Behaviour 140:371-385.

Wrangham RW. 1980. An ecological model of female-bonded primate groups. Behaviour 75:262-300. 